\title{
The cost of care in cystic fibrosis
}

The increasing length of survival of patients with cystic fibrosis will lead to larger numbers of patients in whom the major management problem is respiratory infection, particularly with Pseudomonas aeruginosa. ${ }^{1}$ There are many factors in the improved survival rate, including use of pancreatic enzyme supplements, aggressive antibiotic treatment regimens, and nutritional policies. There is, however, an international consensus and experience suggesting that the major factor determining improved survival in such patients is the coordinated management at specialised centres. ${ }^{2-4}$

In the United Kingdom centres have developed over many years, mainly for children but more recently for adults too. The development of centres for adults has been supported by the British Thoracic Society, the Association for Cystic Fibrosis Adults, and the Royal College of Physicians. ${ }^{5}$ In its report the Royal College of Physicians recommended a centre for each health region, which would act as a resource centre and a focus for the shared care of patients with their local physician. The report also recommended standards of care, adequate staffing, use of audit, and adequate funding. The development of centres has been halted by the withdrawal of regional status from some established centres and the implementation of "contracting," which aims to allocate costs accurately to the services offered as outlined in the Government's White Paper for England and Wales Working for Patients.

In this issue of Thorax (p 684) Robson et al ${ }^{6}$ rise to this challenge and also address the problem of poor information on costs, which largely undermines the principle of precise allocation of costs in the National Health Service. Using estimates based on a careful assessment of the allocation of staff and resources to adults with cystic fibrosis, they produced a scale of costs related to the whole service and specifically to different clinical categories of severity of pulmonary disease. Although there may be deficiencies in this approach it represents a comprehensive attempt to define such costs, which is of paramount importance to centres as most of their patients usually come from outside their district. Clearly, relating costs to severity of pulmonary disease is an important concept that must be understood by the purchaser and provider authorities, particularly because the cost of individual patients will increase as the disorder progresses. The experience of many physicians is that this has not so far been an approach that is widely understood or accepted. Failure to appreciate this variation in cost between patients may lead to extreme "skewing" of budgets in directorates of medicine or respiratory medicine and, possibly, result in inadequate allocation of funds for the currently accepted standard of care for patients with cystic fibrosis.

Physicians caring for patients with cystic fibrosis have a primary responsibility to provide optimal clinical management and also to ensure that colleagues in management and administration understand that patients with cystic fibrosis, though small in number, are expensive to manage if accepted standards of care are to be maintained. It is important to emphasise that a centre is not defined by the number of patients attending a given clinic but rather by the range of services available and the accummulated experience of the staff dealing with large numbers of patients. This particular benefit cannot be offered easily by physicians with small numbers of patients, although they can provide shared care of appropriate standard by working with their colleagues in specialist centres.

Centres for both adults and children are likely to be needed for some considerable time. As new treatments, such as specific anti-inflammatory and membrane regulatory drugs and gene replacement therapy, become available there will be a greater need for specialist centres that can organise and regulate the provision of such treatment ${ }^{1}$ to modest numbers of patients. The approach of Robson et $a l^{6}$ is a useful guide for physicians running specialist centres, for those engaged in shared care or wishing to refer patients to centres, and for health authorities wishing to start a specialist centre. With some modification for local conditions, these costings can be used as a starting point for discussing costs with both provider and procurer authorities in the National Health Service.

D J SHALE

Section of Respiratory Medicine, University of $W$ ales College of Medicine, Llandough Hospital, Penarth CF6 1 XX

Reprint requests to: Professor D J Shale

1 Elborn JS, Shale DJ, Britton JR. Cystic fibrosis: current survival and population estimates to the year 2000. Thorax 1991;46:881-5.

2 British Paediatric Association Working Party on Cystic Fibrosis. Cystic fibrosis in the United Kingdom 1977-1985: an improving picture. $B M J$ 1988;297:1599-602.

3 Phelan PD, Bowes G. Cystic fibrosis in Melbourne. Thorax 1991;46:383-4. 4 Koch C, Høiby N. Cystic fibrosis in Copenhagen. Thorax 1991;46:385-6.

5 Royal College of Physicians. Cystic fibrosis in adults: recommendations for care of patients in the United Kingdom. London: Royal College of Physicians of London, 1990 .

6 Robson M, Abbott J, Webb K, Dodd M, Walsworth-Bell J. A cost description of an adult cystic fibrosis unit and cost analysis of patient categories. Thorax 1992;47:684-9. 